\title{
A Method for Comparing the Fatigue Performance of Forged AZ80 Magnesium
}

\author{
Andrew Gryguć ${ }^{1, *} \mathbb{D}$, Seyed Behzad Behravesh ${ }^{1}$, Hamid Jahed ${ }^{1}{ }^{1}$, Mary Wells ${ }^{1}$, Bruce Williams ${ }^{2}$, Rudy Gruber ${ }^{3}$, \\ Alex Duquette ${ }^{3}$, Tom Sparrow ${ }^{3}$, Jim Prsa ${ }^{3}$ and Xuming $\mathrm{Su}^{4}$ \\ 1 Fatigue and Stress Analysis Lab, Department of Mechanical \& Mechatronics Engineering, \\ University of Waterloo, Waterloo, ON N2L 3G1, Canada; sbbehravesh@uwaterloo.ca (S.B.B.); \\ hamid.jahed@uwaterloo.ca (H.J.); mawells@uwaterloo.ca (M.W.) \\ 2 Canmet MATERIALS, Natural Resources Canada, Hamilton, ON L8P 0A1, Canada; \\ bruce.williams@canada.ca \\ 3 Multimatic Technical Centre, Markham, ON L3R 5E5, Canada; rgruber@multimatic.com (R.G.); \\ aduquett@multimatic.com (A.D.); tsparrow@multimatic.com (T.S.); jprsa@multimatic.com (J.P.) \\ 4 Ford Research and Innovation Center, Dearborn, MI 48124, USA; xumgsu@yahoo.com \\ * Correspondence: agryguc@uwaterloo.ca; Tel.: +1-647-280-9510
}

check for updates

Citation: Gryguć, A.; Behravesh, S.B.; Jahed, H.; Wells, M.; Williams, B.; Gruber, R.; Duquette, A.; Sparrow, T.; Prsa, J.; Su, X. A Method for Comparing the Fatigue Performance of Forged AZ80 Magnesium. Metals 2021, 11, 1290. https://doi.org/ $10.3390 /$ met11081290

Academic Editors: Antonio Mateo and Marcello Cabibbo

Received: 13 June 2021

Accepted: 28 July 2021

Published: 16 August 2021

Publisher's Note: MDPI stays neutral with regard to jurisdictional claims in published maps and institutional affiliations.

Copyright: (c) 2021 by the authors. Licensee MDPI, Basel, Switzerland. This article is an open access article distributed under the terms and conditions of the Creative Commons Attribution (CC BY) license (https:// creativecommons.org/licenses/by/ $4.0 /)$.
Abstract: A closed die forging process was developed to successfully forge an automotive suspension component from AZ80 Mg at a variety of different forging temperatures $\left(300{ }^{\circ} \mathrm{C}, 450{ }^{\circ} \mathrm{C}\right)$. The properties of the forged component were compared and contrasted with other research works on forged AZ80 Mg at both an intermediate forging and full-scale component forging level. The monotonic response, as well as the stress and strain-controlled fatigue behaviours, were characterized for the forged materials. Stress, strain and energy-based fatigue data were used as a basis for comparison of the durability performance. The effects of the starting material, forging temperature, forging geometry/configuration were all studied and aided in developing a deeper understanding of the process-structure-properties relationship. In general, there is a larger improvement in the material properties due to forging with cast base material as the microstructural modification which enhances both the strength and ductility is more pronounced. In general, the optimum fatigue properties were achieved by using extruded base-material and forging using a closed-die process at higher strain rates and lower temperatures. The merits and drawbacks of various fatigue damage parameters (FDP's) were investigated for predicting the fatigue behaviour of die-forged AZ80 Mg components, of those investigated, strain energy density (SED) proved to be the most robust method of comparison.

Keywords: magnesium; forging; fatigue; AZ80; LCF; HCF; texture; $\varepsilon-N$ fatigue; S-N fatigue

\section{Introduction}

The successful utilization of lightweight materials in structural applications is an engineering problem that requires a thorough understanding of the service environment of the component to fully achieve an optimal solution. Typically, Mg components manufactured using traditional casting methods were utilized in applications where they were not significantly load-bearing and could offer significant reduction in mass compared to other structural metals (due to $\mathrm{Mg}^{\prime}$ 's low density). However, this was done without specific effort put into designing the manufacturing process, controlling the resulting material microstructure, or optimizing the component geometry specifically for the applicationspecific service loads. However, more recently, magnesium alloys have been explored for usage in structural applications in the aerospace and automotive industries, as their low density and high specific strength make them ideal for components where lightweight is a priority. Generally, wrought forms of magnesium have been renowned for offering improved strength and ductility as they do not suffer from the manufacturing defects and coarse microstructure typical of cast manufacturing methods. Forging $\mathrm{Mg}$ to produce nearnet shape components can offer substantial benefit and facilitate the reliable usage of $\mathrm{Mg}$ 
in structural fatigue critical components. This has necessitated an immense work towards understanding the complex structural behaviour of forged magnesium components as well as the development of the forging process to optimize the resulting material structure, properties and performance.

Recent work on investigating the feasibility of forging have been conducted specifically focusing on AZ80 Mg as it has good forgeability, and heat-treatability ideal for near net shape of fatigue critical components [1,2]. Characterization of the as-forged properties of AZ80 forged components in recent years has become more widespread in literature. Many studies have focused on the characterization of the monotonic structural properties of forged AZ80 Mg, in open die forgings [3,4] as well as for closed die forged components such as wheels [5-7], aerospace components [7-10], and finally, automotive structural components [11-20]. In general, the main focus of these studies was the feasibility of achieving adequate material flow to produce the desired forged shape, whilst characterizing the resulting microstructure and quasi-static material properties. The processing conditions for the forging process, in general, can be broadly decomposed into being thermal or mechanical in nature; the most significant thermal process parameter is the forging temperature (ranging from 250 to $450{ }^{\circ} \mathrm{C}$ for AZ80 Mg) and the mechanical process parameters are the strain rate $\left(0.075 \mathrm{~s}^{-1}-150 \mathrm{~s}^{-1}\right)$ and equivalent strain $(50-200 \%)$ for the aforementioned studies which were reviewed in a recent work by Papenberg et al. [1]. In the majority of the available literature, the selection of these parameters has not been optimized in each study; in general, the temperature selection was such that it was high enough to provide sufficient material flow whilst not inducing any incipient melting defects, and the rate was constrained by pragmatic limitations of the forging equipment and avoiding edge cracking of the billet. Several recent works by Gryguć et al. [3,4,15-19,21-24] have investigated varying the processing parameters of $\mathrm{Mg}$ forging with the specific objective of improving the strength, fatigue performance, and improving the homogeneity of properties throughout the forging.

This work aims to compare and contrast the existing literature of forged AZ80 Mg with the mechanical and fatigue properties of an industrially viable automotive suspension component (front lower control arm) that has had its manufacturing process parameters intelligently optimized for the application. Furthermore, presented is a discussion on a suitable method of comparison of the fatigue properties of forged AZ80 Mg components with respect to the inherent complexities associated with the geometry and spatially varying thermomechanical conditions.

\section{Experimental Setup}

The material used in this investigation was commercially available AZ80 Mg extruded billet $(8.0 \pm 0.2 \%$ aluminium content, with other elements' composition as per ASTM B91-12 standard). The material was received from Magnesium Elektron Ltd. (Manchester, United Kingdom) in the as-fabricated condition. The dimension of the extruded billet was a diameter of $63.5 \mathrm{~mm}$ and a length of $1000 \mathrm{~mm}$. The forging was conducted at CanmetMATERIALS (Hamilton, ON, Canada) using the billets which were cut down to a length of $680 \mathrm{~mm}$. The billets were pre-bent at an elevated temperature of $300{ }^{\circ} \mathrm{C}$ to an angle of $108^{\circ}$ in a pre-forming step using a mandrel bender to achieve the rough general shape and curvature of the component (step 2 in Figure 1). They then heated again to $300{ }^{\circ} \mathrm{C}$ for $3 \mathrm{~h}$ prior to flattening (step 3 ) to redistribute the material in preparation for the single-step closed-die forging. The flattened billet was then heated to the target forging temperature ( 300 and $450{ }^{\circ} \mathrm{C}$ ) for $1.5 \mathrm{~h}$ (to allow any thermal gradients to decay) and isothermally forged using a 1500-ton hydraulic press using profiled upper and lower dies that were heated with complex internal geometry representing an automotive suspension lower control arm (step 4). Graphite lubricate was used on the die and billet to reduce friction, sticking and promote material flow. The orientation of the billet to the press was such that the radial direction was along the direction of the press stroke (i.e., the direction of forging was parallel to the radial direction of the billet). Forging was carried out in a 
single step at a displacement rate of $2.1-4.2 \mathrm{~mm} / \mathrm{s}$, and they were allowed to air cool with no additional post-heat treatments.
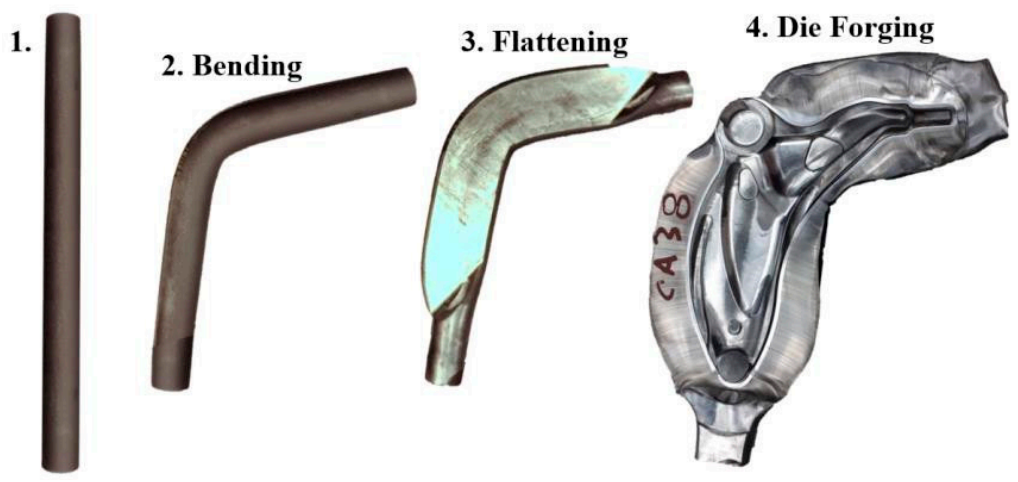

Figure 1. Plan view of extruded billet during different stages of forging operation to achieve final component (prior to machining of the flash).

Tensile monotonic and fatigue test samples were utilized with geometries according to Roostaei et al. [25] and a $4 \mathrm{~mm}$ thickness, these were machined from various locations throughout closed die forged components. There were 18 test samples that were extracted from 18 different locations throughout each of the closed die forging (see Figure 2), all with varying thermomechanical histories. One component forged at each temperature was dedicated to stress-controlled fatigue testing where 10 samples are presented for the $300{ }^{\circ} \mathrm{C}$ forging and 8 for the $450{ }^{\circ} \mathrm{C}$ forging. Strain-controlled tests were performed on 14 different samples extracted from another component forged at $300{ }^{\circ} \mathrm{C}$. The remainder of the original 18 test samples from each component were used for monotonic testing to understand the spatial variation in strength and ductility. The test samples had a nominal surface finish of $\mathrm{Ra} \leq 0.2 \mu \mathrm{m}$; however, in practice, the actual roughness was substantially less, around $0.05 \mu \mathrm{m}$. These samples were later utilized for quasi-static and cyclic (stress-controlled) testing. The quasi-static tensile tests were performed according to ASTM standard E8/E8M-15a using an MTS 810 Servo-Hydraulic test machine operating in displacement control mode with a displacement rate of $1 \mathrm{~mm} / \mathrm{min}$. Strain measurement was accomplished using a GOM ARAMIS 3D 5MP DIC system which passively functioned to measure the average axial strain on the surface of the gauge section of the sample throughout the duration of the test. The fatigue tests were performed as per ASTM E466-15 in an ambient environment using an MTS 810 Servo-Hydraulic test machine operating in stress control mode at a frequency range of $0.5 \mathrm{~Hz}$ to $60 \mathrm{~Hz}$ depending on the stress amplitude to maintain an approximately consistent loading rate between all tests. The strain was measured throughout the first 10,000 cycles using an MTS 632.26 extensometer with an 8-mm gauge and travel of $\pm 1.2 \mathrm{~mm}$ until stabilization of the cyclic hysteresis loop was achieved. The tests were conducted at zero mean stress (i.e., $R_{L}=-1$, fully reversed stress cycle) and stress amplitudes of between $140 \mathrm{MPa}$ and $180 \mathrm{MPa}$. The failure criteria for the tests were considered to be the final rupture of the specimen gauge section.

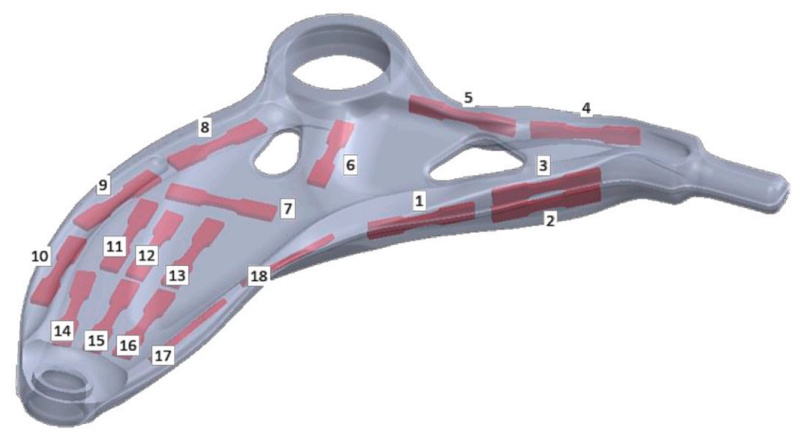

Figure 2. Sample extraction schematic from AZ80 Mg die-forged component. 


\section{Results and Discussion}

\subsection{Structure-Property Relationship (Effect of Material Modification)}

Some of the favourable aspects of selecting forging as a "near net-shape" manufacturing process is the reduction in defects common with casting (such as closure of pores), and in the case of the AZ family of Mg alloys, the refinement in size and distribution of second phase particles [1]. Furthermore, the thermomechanical processing can act as a grain refinement mechanism and given sufficient temperature and strain rate, can promote dynamic recrystallization of the cast materials characteristic dendritic microstructure. This recrystallization process often has implications on the texture direction as well as its overall intensity [3]. The effect that forging of AZ80 Mg has on the resulting microstructure is linked to several factors, of which, the process parameters (thermal and mechanical), material flow, and starting microstructure are considered to be most significant. More specifically, there exists a relationship between the forging temperature, strain rate, total strain and the level of material modification that occurs as a result of forging. As-cast materials, undergo the most significant modification of microstructure, as if sufficient conditions are met, the material will recrystallize from a cast-dendritic microstructure to a more equiaxed polycrystalline microstructure similar to other wrought forms of AZ80 Mg [26,27]. To further highlight the benefits of forging, General Motors prototyped a similar suspension component to that presented in this current study using a low-pressure die-casting process of AZ91 Mg alloy and the resulting yield strength and failure elongation were $92.2 \mathrm{MPa}$ and $3.4 \%$ which can be considered to be in a class inferior to the forged materials investigated here [28]. Figure 3 illustrates the relationship between ductility and yield strength of as-forged AZ80, processed via a variety of different forging temperatures, rates, geometries and starting microstructures. Furthermore, since local thermomechanical history of these aforementioned state variables can be highly non-uniform in nature throughout the forging process, being both a function of time and location within the die-forging, the reported properties have a wide range of temperature, strain rate and total deformation. Thus, they have been grouped into categories of starting microstructure for clarity in illustrating the structure-property relationship of forged AZ80 Mg. It can be observed that, in general, the strength is superior when the starting material for the die forging has an extruded microstructure. Relative to cast-forged material, the ductility is also enhanced, but to a lesser degree. The present study data which also utilized extruded base material, falls within the range of data from other studies within literature. The general trend that can be observed that higher strength material generally is less ductile. There exists one reported cast-forged condition which is grossly inferior to all others presented $\left(\sigma_{Y}=110.7 \mathrm{MPa}\right.$, $\varepsilon_{\text {FAIL }}=7.2 \%$ ), the reasoning being that its forging condition was not sufficiently favorable to recrystallize the cast-dendritic microstructure and modify the properties significantly from the base as-cast material $\left(\sigma_{Y}=92.8 \mathrm{MPa}, \varepsilon_{\mathrm{FAIL}}=7.4 \%\right)[16]$.

From a fatigue perspective, the structure-property relationship plays a similar role, where increased yield strength generally has a positive effect on improving fatigue life. However, since the nature of fatigue damage in AZ80 Mg is highly dependent on the nature of plastic deformation mechanisms, in certain cases there exists an intersection point in the property curves where the effect of the material modification becomes more complex and dependent on both the life domain and type of loading [17]. For example, Figure 4 highlights the traditional strain-life $(\varepsilon-\mathrm{N})$ property curve that is generated using fully reversed strain-controlled fatigue tests for a variety of different forms of AZ80 Mg, cast [3], extruded [17], cast-forged [3] and extruded forged [17]. Please note that the forging conditions vary between each forged variety, as once again, the data have been grouped into categories of starting microstructure for clarity in illustrating the structure-property relationship of forged AZ $80 \mathrm{Mg}$. It can be observed that there is a dramatic improvement in the life in as-cast material once forged, over the entire range of presented strain amplitudes. For the extruded material, however, it is well-known that the base material is anisotropic, thus the fatigue properties differ in each material direction, with the extrusion direction (ED) exhibiting a higher yield strength resulting in longer life in the high cycle fatigue 
(HCF) regime, and the transverse direction (TD) having enhanced ductility corresponding to lower cyclic stresses and longer life in the low cycle fatigue (LCF) regime. The transition threshold (or curve intersection point) between the ED and RD demonstrates when the effects of strength and ductility on the fatigue damage mechanism are approximately equal. Once forged, the extruded-forged material exhibits an enhancement in life in the HCF regime, displaying the longest life at strain amplitudes $\varepsilon_{\mathrm{A}}<0.4 \%$. The individual data for the current study are shown to illustrate the amount of variability relative to the fitted $\varepsilon-\mathrm{N}$ property curve generated using the well-known Coffin-Manson approach. This variability is linked to both the stochastic nature of fatigue, and more importantly, the variation in thermomechanical histories for the location for which each sample was extracted from the forging. This interaction of the process parameters upon the resulting as-forged properties will subsequently be discussed in more detail in Section 3.2. Furthermore, the applications of utilizing strain amplitude as a damage parameter for forged AZ80 Mg will be discussed in Section 3.3.

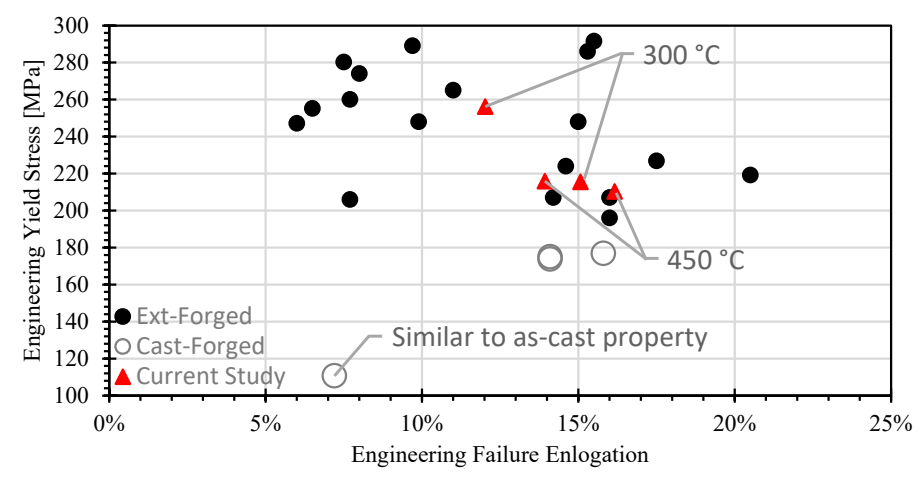

Figure 3. Relationship between ductility (failure elongation) and strength (yield stress) for forged AZ80 Magnesium (subdivided into various starting material conditions). The current study denotes properties extracted from various locations of the extruded then die-forged automotive suspension control arm forged at various temperatures $\left(300^{\circ} \mathrm{C}\right.$ and $\left.450{ }^{\circ} \mathrm{C}\right)$. For reference, extruded-forged data can be found in the following studies $[5-13,16]$, cast-forged from $[3,16]$.

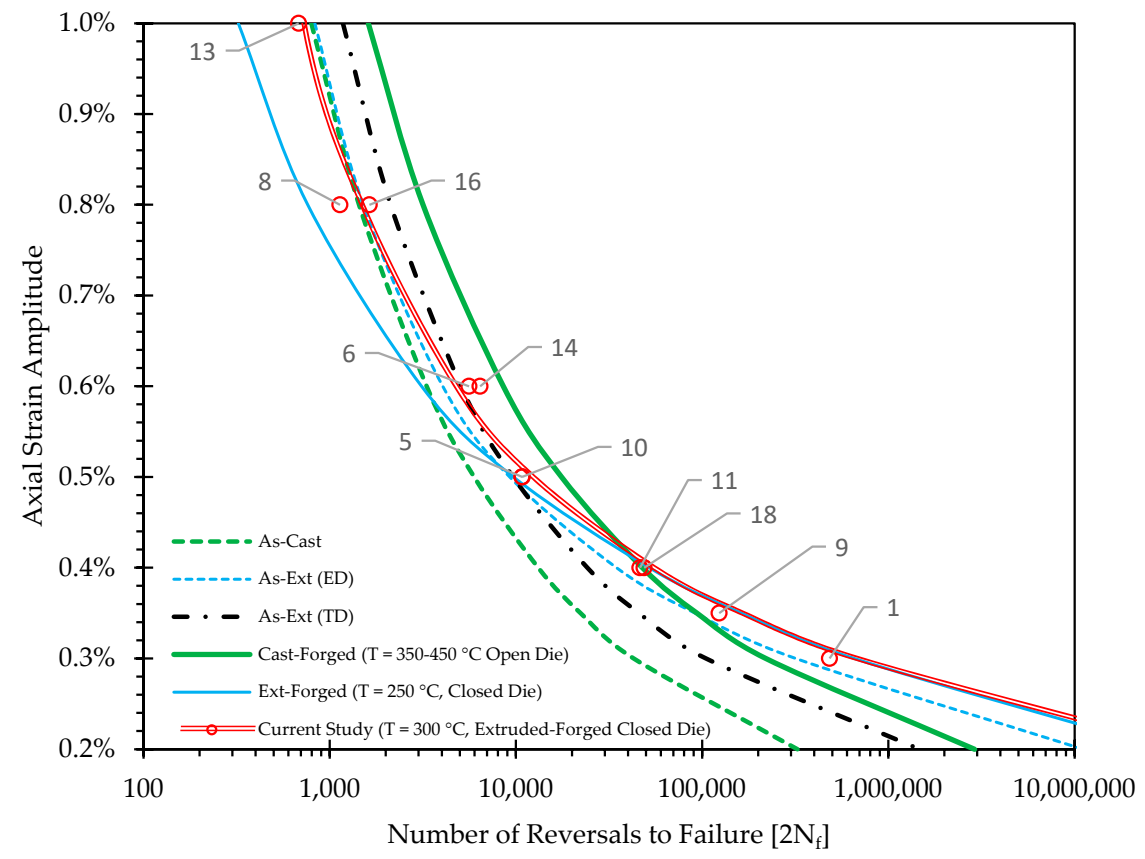

Figure 4. Summary state-of-the-art literature of $\varepsilon$-N curves for a variety of different AZ80 Mg material conditions, dashed lines are average starting material conditions, solid lines are average "as-forged" properties. Current study is denoted in red, with locations indicated as per Figure 2. 
Similarly, Figure 5 illustrates the relationship between total strain energy density (total SED: summation of plastic and elastic energy per cycle, for the stabilized response), and Number of Reversals to Failure. The same AZ80 Mg material conditions are presented, cast [3], extruded [17], cast-forged [3] and extruded forged [17]. Once again, the individual data for the current study are shown to illustrate the amount of variability relative to the fitted E-N property curve generated using the well-known Jahed-Varvani approach [29]. Similar observations can be drawn to those from the $\varepsilon$-N properties, with the extrudedforged material exhibiting a longer life for a given strain energy density in the HCF regime, with a similar transition threshold between plastic and elastic behaviour being the salient deformation mechanisms. Of particular interest, however, is the apparent similarity in damage tolerance of the as-extruded material in both material directions (ED/RD) in the LCF regime. More specifically, the damage tolerance of the as-extruded material is insensitive to the material direction and can be considered to be isotropic at high levels of plastic deformation $\left(\mathrm{E}_{\mathrm{T}}>2.0 \mathrm{MJ} / \mathrm{m}^{3}\right)$, at least on the basis of using strain energy density as a fatigue damage parameter. This observation delves deeper into the structure-property relationship of $\mathrm{AZ} 80 \mathrm{Mg}$, as within the same material condition, we can observe the effects of texture on the fatigue properties, and in what domain of fatigue (LCF/HCF) they are most significant. This variability in the individual data for the current study is once again linked to variation in thermomechanical histories for the location for which each sample was extracted from the forging, and the associated variations in the damage tolerance of the resulting material. The applications of utilizing total strain energy density as a damage parameter for forged AZ80 Mg will be discussed in Section 3.3.

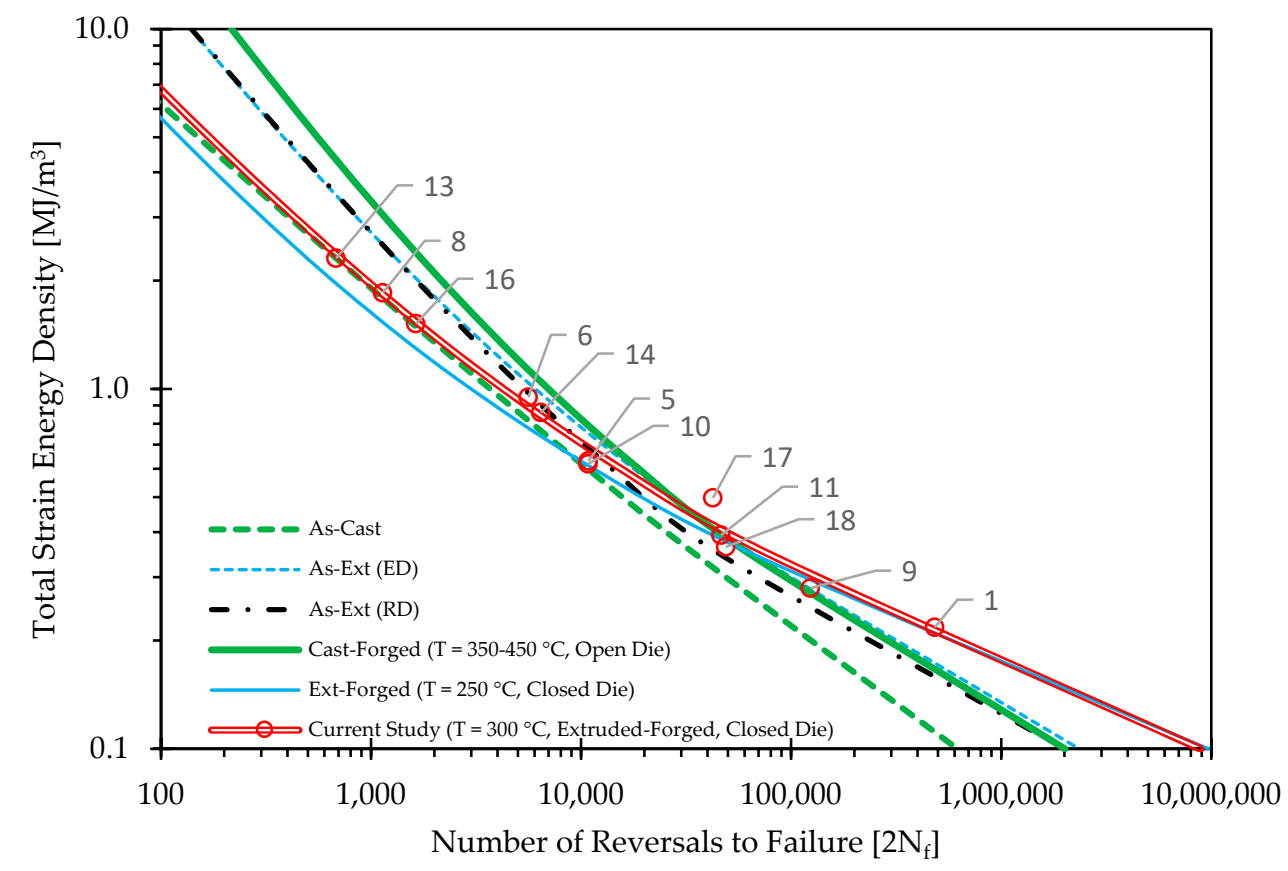

Figure 5. Summary of state-of-the-art literature Energy-Life curves for a variety of different AZ80 $\mathrm{Mg}$ material conditions, dashed lines are average starting material conditions, solid lines are average "as-forged" properties. Current study is denoted in red, with locations indicated per Figure 2.

\subsection{Process-Property Relationship (Effect of Process Parameters)}

Intrinsic to the forging process are a number of state variables (primarily thermal and mechanical in nature) which can vary as a function of time (i.e., from beginning to end of the deformation), and geometry (location, and local material flow conditions). These temporal and spatial variations lead to differences in the properties throughout the forged product and depending on the process parameters and the component geometry, can be highly 3-dimensional in nature. The influence of the local forging direction (or direction 
dominated by compressive loading) on the resulting texture of the as-forged material was previously explored by Gryguć et al. [16,17] in medium-scale I-beam style forgings. Those studies concluded that the favourable texture modification due to forging was the alignment of the c-axis of the hexagonal-closed-packed (HCP) crystal to be parallel with the local forging direction (or direction of dominant compressive loading), which is often normal to the die surface in relatively thin forgings at areas closer to the surface of the forged component. Depending on the process temperature, and local thermal history (accounting for the heat of deformation), the material recrystallization process may be highly nonuniform and heterogeneous in nature, resulting in spatially varying microstructure, texture and thus mechanical properties. Figure 6 illustrates the relationship between the primary thermal process parameter (the target forging temperature) and the resulting yield strength for a variety of forged AZ80 Mg. Similar AZ80 Mg material conditions are presented, cast [3], extruded [17], cast-forged [3] and extruded forged [17], and they are once again grouped into categories of starting microstructure for clarity in illustrating the processproperty relationship of forged AZ80 Mg. It can be observed that there is a general trend (albeit it, quite weak) where lower forging temperatures produce material with higher strength. This relatively poor correlation will subsequently be discussed in relation to the recrystalization mechanisms present during the forging process. For wrought forms of base material (i.e., extruded), forging at higher temperatures can result in grain growth (resulting in lower strength) and lower temperatures the potential for shear cracking (from reduced ductility) [30]. Of the studies presented, all were isothermal in nature (forging dies and billet are at the same temperature), and the forging temperature window ranges $250-450{ }^{\circ} \mathrm{C}$. Beneath $250{ }^{\circ} \mathrm{C}$, edge cracking and poor formability result as only a few deformation mechanisms become active, and large strain is not achievable [31]. At temperatures higher than $427{ }^{\circ} \mathrm{C}$, incipient melting of the $\mathrm{Mg}_{17} \mathrm{Al}_{12}$ eutectic phase will occur near the grain boundary [13,32]. This propensity towards incipient melting at higher processing temperatures for $\mathrm{AZ}$ series $\mathrm{Mg}$ alloys limits them from being extruded quickly, as compared to other structural metals, the processing window is quite narrow; however, this is not as limiting with die forging as the local deformation rates are typically smaller [33]. Chaudhury et al. suggest for AZ80 Mg, a non-isothermal forging process with a temperature window of $290-400{ }^{\circ} \mathrm{C}$ for the billet, and $205-290{ }^{\circ} \mathrm{C}$ for the forging dies to avoid these aforementioned types of defects that can result in the as-forged material [30] which agrees well with the trend seen in the current study.

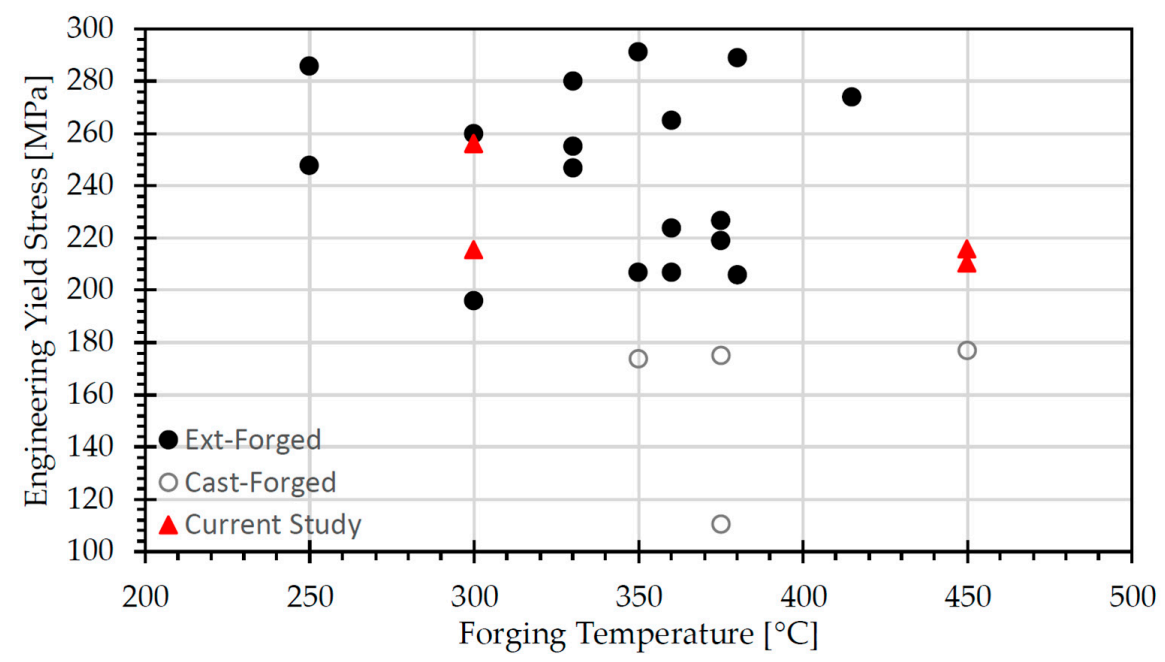

Figure 6. Relationship between primary thermal process parameter (forging temperature) and resulting yield strength of AZ80 Mg after forging (subdivided into various starting material conditions). The current study denotes properties extracted from various locations of the extruded then die-forged automotive suspension control arm forged at various temperatures $\left(300^{\circ} \mathrm{C}\right.$ and $\left.450{ }^{\circ} \mathrm{C}\right)$. For reference, extruded- forged data can found in the following studies [5-13,16], cast-forged from $[3,16]$. 
The stress-controlled fatigue response of the closed-die forged AZ80 Mg automotive suspension component is illustrated in Figure 7 for the two target forging temperatures that were investigated in this current study. It can be easily observed that for virtually all of the tests performed, for a given stress amplitude, the lower forging temperature $\left(300^{\circ} \mathrm{C}\right)$ provides a longer life in comparison with those components which were forged at $450{ }^{\circ} \mathrm{C}$. In general, the lower forging temperature of $300{ }^{\circ} \mathrm{C}$ shows an improvement in life of $\sim 3 \times$ longer at $180 \mathrm{MPa}$ and $\sim 7 \times$ longer at $140 \mathrm{MPa}$, with the more dramatic improvement in the HCF as the superior strength contributes to lower fatigue damage and less cyclic plasticity. However, the level of variation in the life for a given stress amplitude increases at the lower forging temperature, indicative of a less uniform fatigue properties throughout the forged component, which can be attributed to a similar effect observed by Gryguć et al. [24] where AZ80 forgings done at lower temperatures exhibit more bimodal grain structures, with spatially varying precipitate content throughout the forging, and higher temperatures lead to increased microstructural homogeneity, lack of precipitate content and overall grain growth. This increase in variability in the fatigue performance of die-forged AZ80 Mg at lower temperatures is obvious here in the current study where the forgings were air-cooled with no additional heat treatment. However, other researchers have investigated controlling the precipitation of second phase particles of AZ80 Mg by immediately quenching the component following forging, then followed by a subsequent aging (T5) treatment, with promising results [30]. In general, a significant component of the variability observed in the properties of the as-forged components stems from the air-cooling following forging, and the resulting variability in local cooling rates throughout the complex geometry of the forged component itself. For this current study, the as-fabricated condition (-F) was intentionally selected as it provides insight into the nature of the resulting microstructure from the forging process itself, providing a better basis for comparison of the thermal process effects. Furthermore, to maintain consistency with the majority of the studies on forged AZ80 in the literature that have been presented here for comparative purposes, we have also characterized the properties in the as-fabricated conditions. The variability resulting from air-cooling, and the effect of artificial aging on both the mechanical properties and fatigue damage mechanisms of closed-die forged AZ80 is an effect that complicates the forging process design and is the focus of current and ongoing work. Furthermore, the pre-heating of the billet prior to step 2,3 and 4 of forging (bending, flattening and die-forging), introduces some unintentional yet complex thermal history resulting in a "pseudo"-aging or solutionizing treatments to the billet prior to forging depending on the target temperature, as the billet is held at various temperatures for a few hours at each step. There inevitably is some impact on the precipitates as a result of this complex thermal history prior to forging, which is further complicated by the fact that the starting microstructure prior to the die forging is then significantly mechanically deformed which can break-up and refine the precipitates, compounding with the effects of DRX. Despite this, the thermal history is only part of the thermomechanical processing history, and the effects of the process variables which are mechanical in nature will be subsequently discussed.

Figure 8, illustrates SEM micrographs highlighting the precipitate morphology of two different locations within the forging that were tested at the same stress amplitude yet exhibited a significantly different number of cycles to failure. The precipitates are continuous in nature and range in both size and morphology, from smaller lozenge/blunted asymmetric hexagonal structure to larger slab-like structures, and they can be observed in the brighter contrast regions in the micrographs with the darker background being the parent matrix. Their chemistry is well-known to be $\mathrm{Mg}_{17} \mathrm{Al}_{12}$ which is quite common in $\mathrm{AZ}$ series $\mathrm{Mg}$ alloys whose $\mathrm{Al}$ content exceeds the critical limit of $6 \mathrm{wt} \%$, thus resulting in precipitation of these intermetallic [34,35]. These findings agree well with those from Lai et al., who performed artificial aging studies on extruded AZ80 Mg and found that smaller lozenge-shaped precipitates (Widmanstätten) occur at aging temperatures of $150-300{ }^{\circ} \mathrm{C}$, and the larger slab-shaped at $250^{\circ} \mathrm{C}$ [34]. These temperature ranges correspond well with 
the approximate temperature history that would have been experienced during air cooling of the forgings that were conducted at a target temperature of $300^{\circ} \mathrm{C}$. They also mention that the second phase sizes and morphologies which precipitate are highly dependent on the temperature and aging time, and in this study since air cooling was employed, both of these parameters would naturally spatially vary throughout the forged component and would be different in location \#3 (Figure 8a) and location \#13 (Figure 8b). Supporting this, is the observation that there is an apparent difference in the uniformity of the distribution in these continuous precipitates between the two locations. In location \#3 (Figure 8a) the precipitate distribution is somewhat striated in the middle of the micrograph, with a nonuniform volume fraction of the second phase, as compared with location \#13 (Figure 8b) which is much more uniform in nature across the entire image. Furthermore, from the higher magnification images, it can be observed that, in general, location \#3 (Figure 8c) has comparatively larger precipitate sizes relative to location \#13 (Figure 8d). A more refined precipitate structure with smaller spacing between particles leads to a higher propensity to resist dislocation movement when plastically deformed which is beneficial to the mechanical properties [34]. Both effects of this increase in uniformity in precipitation distribution and decrease in size in location \#13 (Figure 8b) can contribute to an increase in strength, and fatigue life (as observed in the two samples tested at $160 \mathrm{MPa}$ where there is a difference in life of about $6 \times)[1,34]$ The source of this variation in life has many contributing effects, the most significant of which are: firstly, the effect of the thermal process history on the microstructure and precipitate morphology discussed here; secondly, the equivalent strain imposed by the mechanical deformation during forging which will be subsequently discussed; and finally, the well documented stochastic nature of fatigue.

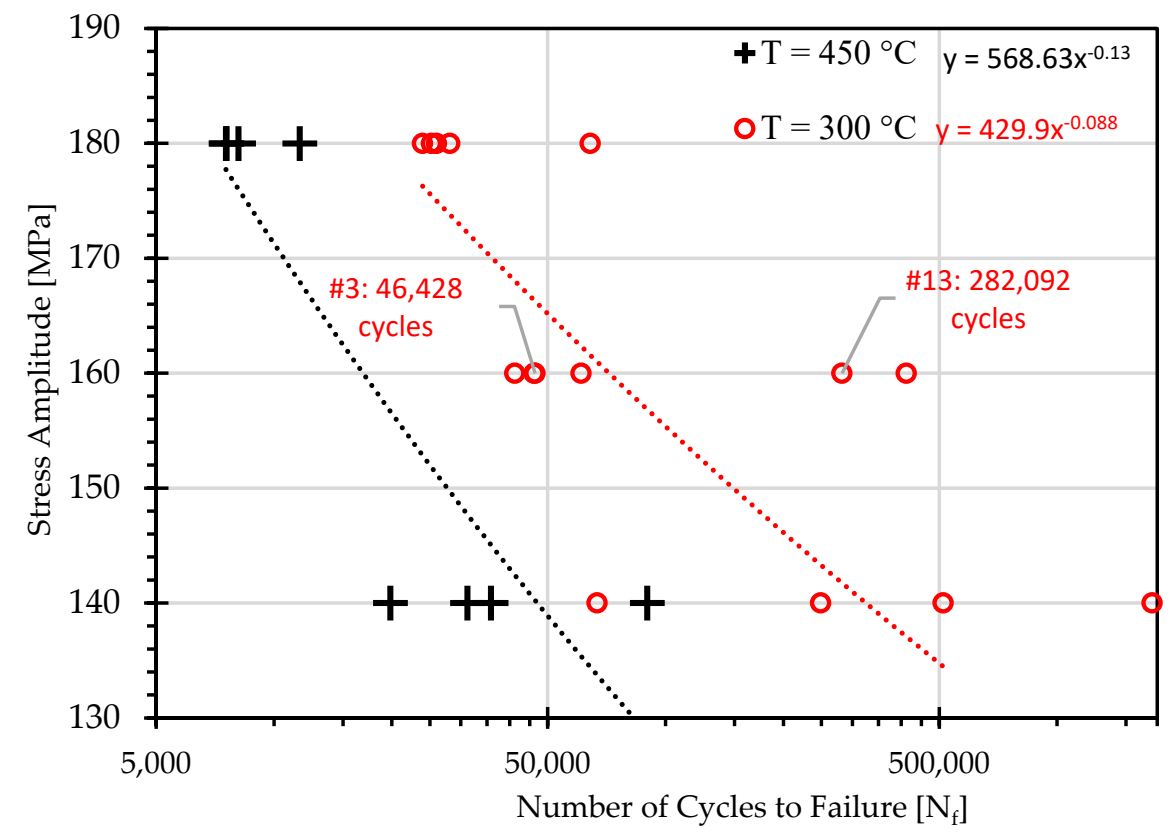

Figure 7. Relationship between the forging temperature and stress-controlled fatigue behaviour for closed-die forged AZ80 Mg automotive suspension component. Location \#3 \& \#13 are highlighted for reference (per Figure 2) as they are subsequently referred to in the SEM micrographs in Figure 8. 


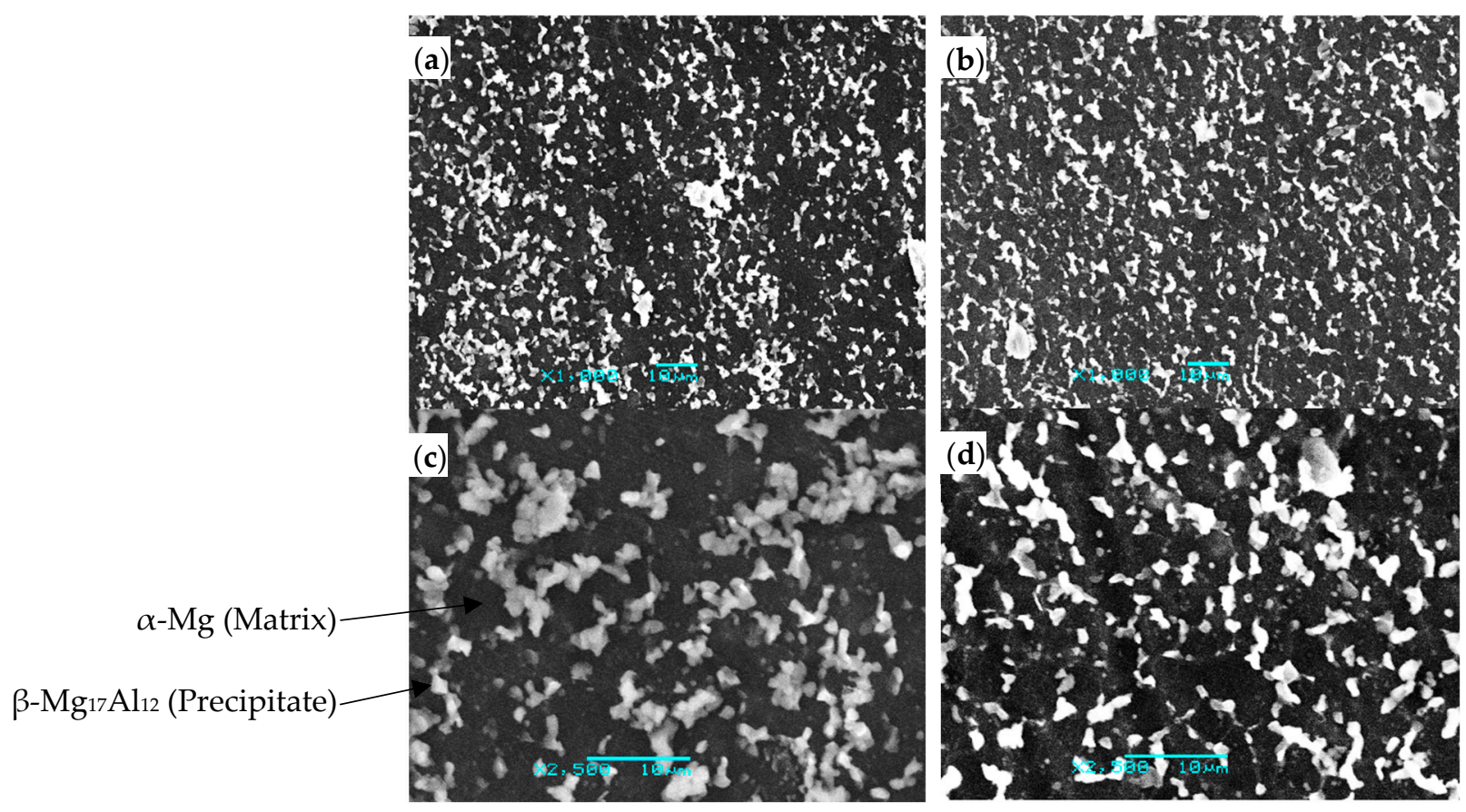

Figure 8. SEM images using a JEOL JSM-6460 (JEOL, Longueuil, QC, Canada) of extruded AZ80 Mg which was then closed-die forged at $300^{\circ} \mathrm{C}$ and air-cooled, in two different locations of the forging (a,c) location \#3, and (b,d) location \#13. Please refer to Figure 2 for referencing each location number to the corresponding location within the forged component.

Figure 9 illustrates the relationship between the primary mechanical process parameter (equivalent plastic strain) and the resulting yield strength of AZ80 Mg after forging. The equivalent plastic strain is generally obtained from some form of numerical simulation of the forging process, the details of which are outside of the scope of this work but are presented for reference only to give a relative indication to the severity of the plastic deformation, and the amount of material modification that has occurred due to the process-related deformation. Some interesting observations can be made regarding the cast-forged materials which require between $\varepsilon_{\text {eq }} \approx 125-175 \%$ to achieve the elevated material property and transition from the as-cast domain of yield strength to the wrought domain of strength. This threshold of equivalent plastic strain (or mechanical deformation) for forging of as-cast AZ80 Mg develops the link between the process-related state variables and the resulting material properties, as previously there was poor correlation between this beneficial material modification and the forging temperature as observed in Figure 6 and the unintuitive increase in both strength and ductility of some cast-forged studies be more similar to those of the wrought domain of AZ80 Mg material properties (seen in Figure 3). Several researchers have found in hot deformation studies that as-cast AZ80 Mg requires a moderate to significant amount of deformation strain to recrystalize its dendritic microstructure, even if the process parameters are favourable to do so. Jiang et al. found in cast AZ80 Mg, that was compressively deformed at $350{ }^{\circ} \mathrm{C}$ to a strain of $\varepsilon_{\text {Ture }}=61 \%$ there still is $\sim 9 \%$ of un dynamically-recrystallized (DRXed) microstructure, and the average un DRXed grain size continually decreases with increasing strain [36]. Other studies, also found similar results, where even at strains of $\varepsilon_{\text {Ture }}>100 \%$, the parent cast microstructure, still was not fully recrystalized $[26,27,37]$. This correlation between increasing mechanical deformation and improvement in structural properties associated with a transformation from a cast-dendritic microstructure to a wrought microstructure resulting from the forging process is obviously only present when the starting base material is as-cast. The reliance on the forging process having a sufficient level of mechanical deformation to augment the material properties is much less important when the starting material is of the as-extruded varieties, as the microstructural modification is less intense [16]. Hence, the modification in fatigue properties in the extruded then forged AZ80 Mg in the current study is predomi- 
nantly due to the increase in strength from a modified texture, refined grain structure and evolved precipitate size/distribution/morphology. However, if the processing conditions during forging are not optimally selected, a dramatic impact can result in the strengthening mechanisms of each of these aforementioned contributing effects. More specifically, if the forging temperature is too high, then grain growth can occur which can result in lower strengths. If the temperature is too low, the pragmatic constraint of poor workability and inadequate die-fill will dominate. The processing window of the current work and the studies presented here is quite narrow and optimizing the forging parameters specifically to achieve the properties which are desirable for the service application is of utmost importance to achieve a holistic improvement in forging process design. Each of these effects and their impact on the property-performance relationship are highly coupled in nature; that is to say, they are commonly inter-related with one another and are frequently not mutually exclusive. Exploration of optimizing this property-performance relationship with a summary of the fatigue characterizations and modelling that was done in the current study will subsequently be discussed in more detail in Section 3.3.

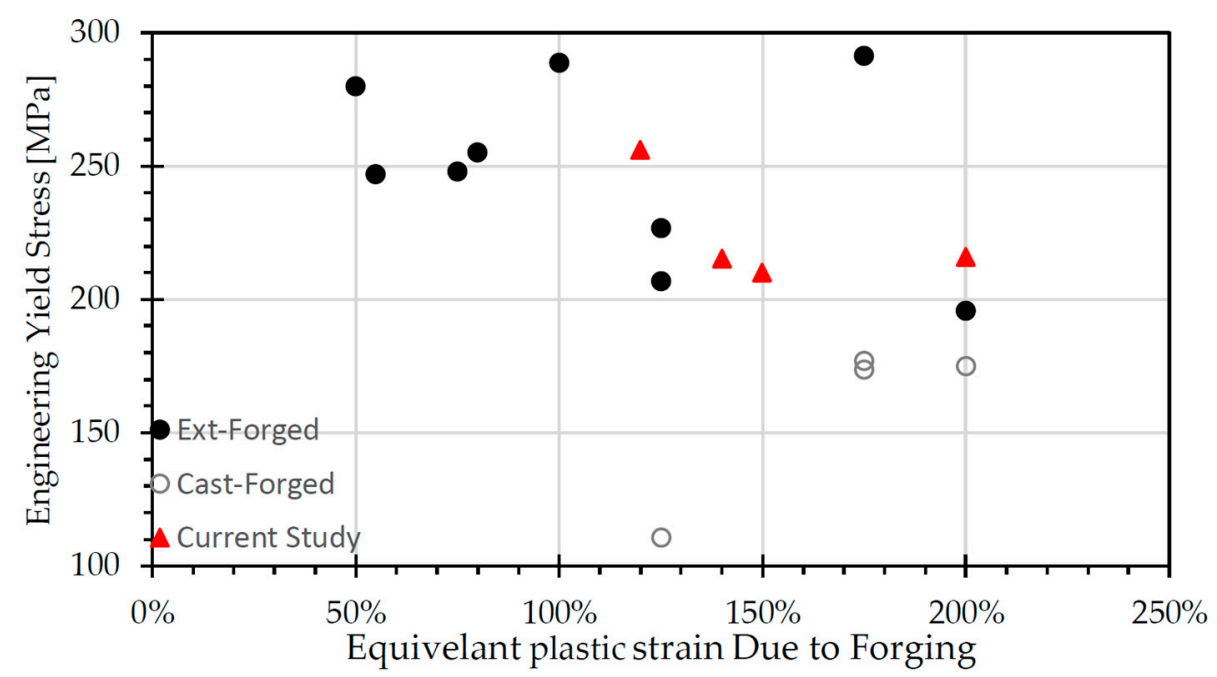

Figure 9. Relationship between primary mechanical process parameter (equivalent local strain due to forging) and resulting yield strength of AZ80 Mg after forging (subdivided into various starting material conditions). The current study denotes properties extracted from various locations of the extruded then die-forged automotive suspension control arm forged at various temperatures $\left(300{ }^{\circ} \mathrm{C}\right.$ and $450{ }^{\circ} \mathrm{C}$ ). For reference, extruded-forged data can be found in the following studies $[5-13,16]$, and cast-forged from $[3,16]$.

\subsection{Property-Performance Relationship (Optimizing the Forging Process)}

The influence of the properties on the performance of the material is an emerging topic in the field of forged $\mathrm{Mg}$ alloys as characterizing the mechanical properties of forged $\mathrm{Mg}$ is now somewhat well understood [1]. Furthermore, optimization of the forging process parameters with an aim to improve the in-service performance of forged $\mathrm{Mg}$ components is an area that shows promise for future work. The influence of the materials structure and the forging process on the structural properties (both monotonic and fatigue) that was previously discussed highlights the impact of the highly complex thermomechanical nature of closed die forging AZ80 Mg to produce intricate 3-dimensional components such as the automotive suspension component presented here in this current study. Since the in-service requirements of the automotive suspension component are highly reliant on its fatigue performance, optimizing the forging process parameters for fatigue critical components is an important contribution of this work. Figure 10 illustrates a typical strainlife $(\varepsilon-\mathrm{N})$ curve for the optimum condition (of those which were investigated), which is $300{ }^{\circ} \mathrm{C}$ for an extruded then closed die forging of an AZ80 Mg automotive suspension component. The Coffin-Manson parameters associated with the response of the forged 
material highlight the representative (or average property) across the entire component. The spatial variation in properties that was previously discussed linked with the variations in thermomechanical history throughout the component are the main contributors towards the data's deviation from the modelled Coffin-Manson type behaviour. Furthermore, the anisotropy associated with the spatial variations in texture throughout the component also contributes to these variations in properties as the fatigue specimen orientation within the forged component also varies due to pragmatic geometrical constraints. Each location in the control arm is denoted in Figure 10 as to develop a link between the property and the performance observed service. The nature of using strain as a basis for comparison of fatigue performance intrinsically penalizes higher strength material as was observed in the extruded-forged material from Figure 4 as the cyclic stresses for a given fully reversed strain cycle will be higher than lower strength locations. This point has been discussed extensively in earlier studies [3,17]. Despite other rudimentary works on characterizing the fatigue of die-forged $\mathrm{Mg}$ full-scale components, to the authors' knowledge, this current work is the first research study conducted which presents strain-controlled fatigue properties, for a forged $\mathrm{Mg}$ component of full-scale industrial relevance (i.e., not research/lab type specimens).

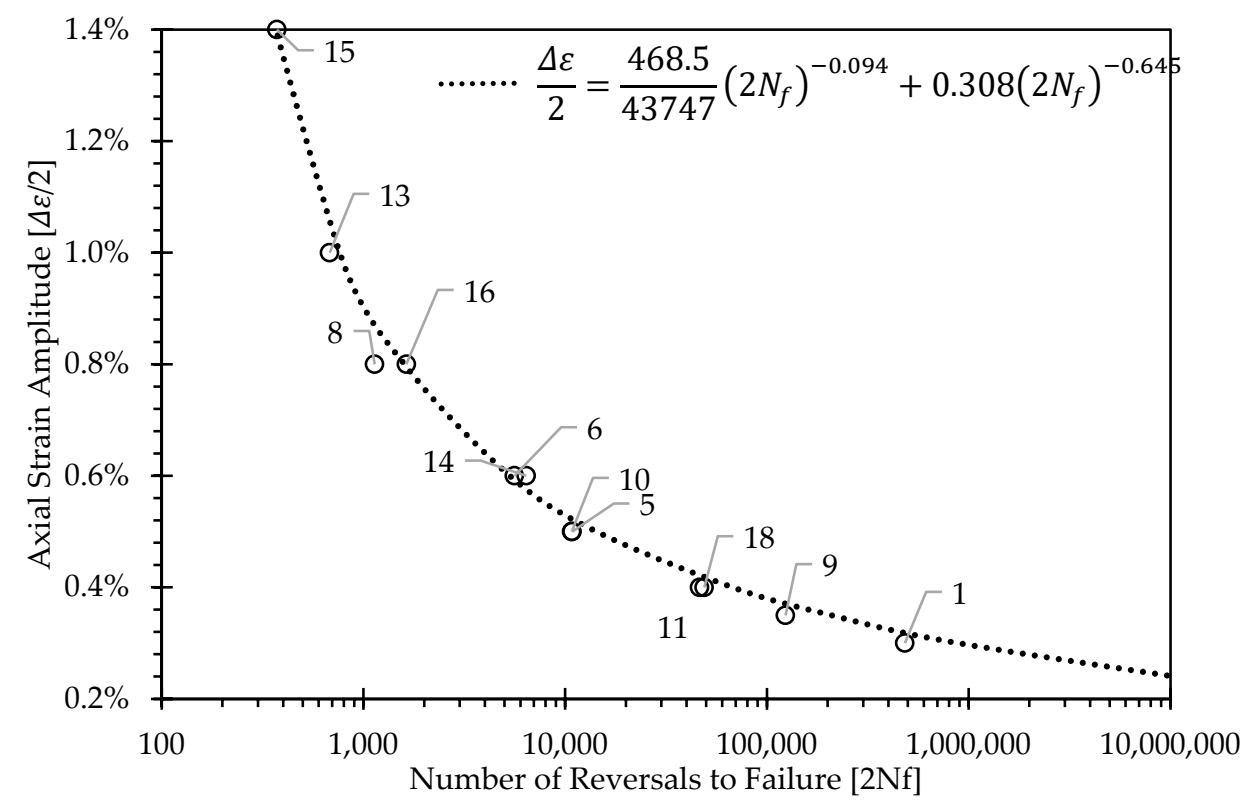

Figure 10. $\varepsilon-\mathrm{N}$ curve for the current component level study (AZ80 Mg, extruded then closed die-forged at $300{ }^{\circ} \mathrm{C}$ ). Various locations throughout the forging are denoted for each data point corresponding to the nomenclature in Figure 2. Denoted by the dashed line is "design curve" which is presented for reference with its equation acting as a $50 \%$ confidence level representative fit to the data. Please refer to Figure 2 for referencing each location number to the corresponding location within the forged component.

Figure 11 illustrates the stress vs. life (S-N) curve for the optimum condition (of those which were investigated), which is $300{ }^{\circ} \mathrm{C}$ for an extruded then closed die forging of an AZ80 Mg automotive suspension component. Denoted are the individual locations throughout the forging, highlighting the spatial variation between each location which can be observed by the disparity in life between locations for a given stress amplitude. A traditional Basquin equation is shown for reference to model the representative behaviour as indicated by the dashed line. However, the stress amplitude as a basis for comparison does not provide a reliable and accurate method to compare the fatigue performance of forged AZ80 Mg components due to the inherent variation in thermomechanical history throughout different locations of the forging which will be subsequently discussed in more detail. 


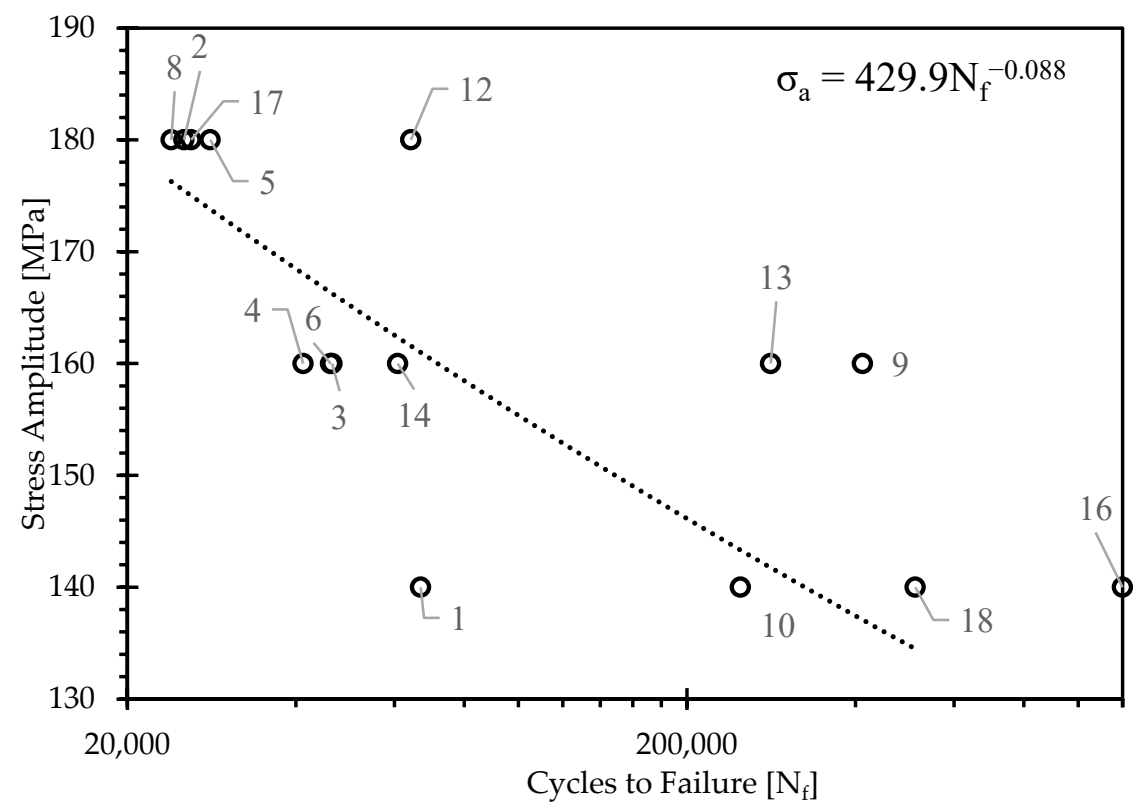

Figure 11. S-N curve for the current component level study (AZ80 Mg, extruded then closed die-forged at $300{ }^{\circ} \mathrm{C}$ ). Various locations throughout the forging are denoted for each data point corresponding to the nomenclature in Figure 2. Denoted by the dashed line is "design curve" which is presented for reference with its equation acting as a representative fit to the data. Please refer to Figure 2 for referencing each location number to the corresponding location within the forged component.

Figure 12 illustrates the relationship between stabilized cyclic total strain energy density (SED) and life extracted from the strain-controlled fatigue tests for the optimum forging condition (of those which were investigated), which is $300{ }^{\circ} \mathrm{C}$ for an extruded then closed die forging of an AZ80 Mg automotive suspension component. It can be observed that there is good correlation between a power-law fit to the data on a loglog plot with only minor scatter surrounding the representative design curve that is presented. This provides some evidence as to the observation that the materials damage tolerance in terms of total SED per cycle for a given life, is constant somewhat regardless of its location within the component (and corresponding variations in thermomechanical history). More specifically, the inherent drawbacks in using either stress (Figure 11) or strain (Figure 10) as a fatigue damage parameter (FDP) for forged AZ80 Mg are not present when using strain energy density, as it reduces the influence of augmented strength due to forging on modelling the cyclic damage. The reasoning for this is using SED as a basis for comparison of fatigue performance does not suffer from the effects of stronger material exhibiting higher cyclic stresses under $\varepsilon$ control, or lower cyclic strains under $\sigma$ control, it instead acts to synergistically incorporate both these effects via the combination of the elastic and plastic components of SED. This allows SED to be a more robust and reliable FDP that is less sensitive to the effects of variations in yield stress caused by texture-induced anisotropy in die-forged AZ80 Mg components. Furthermore, SED as an FDP can also account for the effects upon the changes in cyclic damage mechanism caused by spatially varying microstructure and precipitate content induced by forging process-related thermomechanical histories, however, to a lesser degree. For these reasons, SED has proved to provide a reliable method for predicting the fatigue behaviour of AZ80 die forged components such as the automotive suspension component in this current study. 


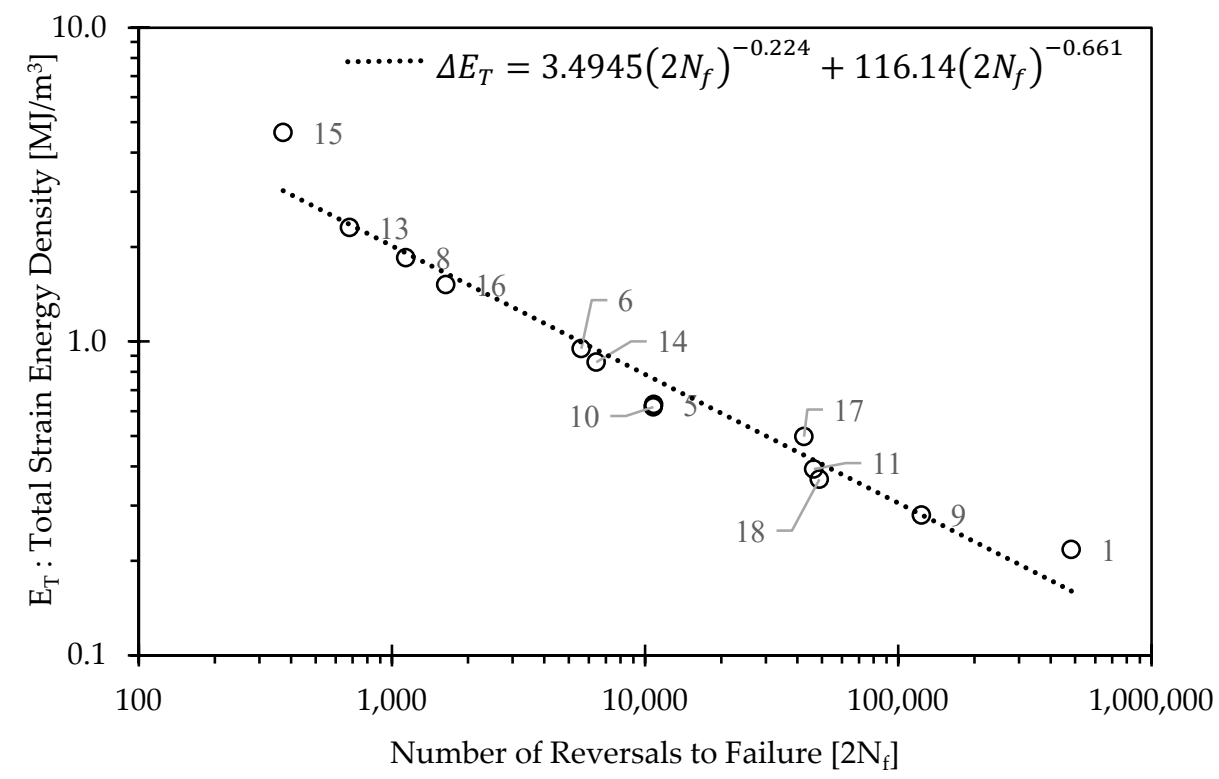

Figure 12. Energy-Life curve for the current component level study (AZ80 Mg, extruded then closed die-forged at $300{ }^{\circ} \mathrm{C}$ ). Various locations throughout the forging are denoted for each data point corresponding to the nomenclature in Figure 2. Denoted by the dashed line is "design curve" which is presented for reference with its equation acting as a $50 \%$ confidence level representative fit to the data. Please refer to Figure 2 for referencing each location number to the corresponding location within the forged component.

\section{Conclusions}

A closed die forging process was developed to successfully forge an automotive suspension component from AZ80 Mg at a variety of different forging temperatures $\left(300{ }^{\circ} \mathrm{C}\right.$, $450^{\circ} \mathrm{C}$ ). The properties of the forged component were compared and contrasted with other research works on forged AZ80 Mg which are quite limited. The monotonic response as well as the stress and strain-controlled fatigue behaviours were characterized for the forged component. A link between the process, structure and properties was developed for the forged component within the context of optimizing them for fatigue critical applications. The merits and drawbacks of various fatigue damage parameters (FDP's) were investigated for predicting the fatigue behaviour of die-forged AZ80 Mg components. Based on these results the following conclusions can be drawn:

1. The effect of forging process-related material modification is more pronounced when the starting material is of the cast variety, and there exists a threshold of both mechanical deformation and thermal history required to achieve the augmentation of mechanical properties associated with forging of AZ80 Mg.

2. Forging of an automotive suspension component of such complex geometry results in the spatial variation in the microstructure, precipitate content, textures, and associated properties throughout the component. This is caused primarily by the non-uniform local thermomechanical history throughout the globally iso-thermal forging process.

3. Of those processing parameters which were both reviewed and investigated, the optimum fatigue properties were achieved by using extruded base-material which was then closed-die forged at $300{ }^{\circ} \mathrm{C}$.

4. Strain Energy Density (SED) was found to be a robust and reliable fatigue damage parameter that is less sensitive to the effects of variations in yield strength caused by texture-induced anisotropy in die-forged AZ80 Mg components.

5. SED as an FDP can also account, to a lesser degree, for the effects upon the changes in cyclic damage mechanism caused by spatially varying microstructure and precipitate content induced by forging process-related thermomechanical histories. 
Author Contributions: Conceptualization, A.G. and H.J.; methodology, A.G.; software, A.G.; investigation, A.G.; resources, A.G., H.J., S.B.B., R.G., A.D., B.W. and X.S.; data curation, A.G.; writingoriginal draft preparation, A.G.; writing-review and editing, A.G., H.J., S.B.B., B.W. and A.D.; visualization, A.G., T.S. and J.P.; supervision, H.J. and M.W.; project administration, H.J. and S.B.B.; funding acquisition, H.J. and S.B.B. All authors have read and agreed to the published version of the manuscript.

Funding: The financial support of the Natural Sciences and Engineering Research Council of Canada (NSERC) through the Automotive Partnership Canada (APC) under APCPJ 459269-13 grant with contributions from Multimatic Technical Centre, Ford Motor Company, and Centerline Windsor are acknowledged.

Data Availability Statement: The data presented in this study are available upon request from the corresponding author.

Acknowledgments: The authors would also like to acknowledge J. McKinley from CanmetMATERIALS for forging trials.

Conflicts of Interest: The authors declare no conflict of interest.

\section{References}

1. Papenberg, N.P.; Gneiger, S.; Weißensteiner, I.; Uggowitzer, P.J.; Pogatscher, S. Mg-Alloys for Forging Applications-A Review. Materials (Basel) 2020, 13, 985. [CrossRef]

2. Ovsyannikov, B.V. Die-Forged Disks for Automobile Wheels in Magnesium Alloys. In Magnesium: Proceedings of the 7th International Conference Magnesium Alloys and Their Application; Kainer, K.U., Ed.; Wiley-VCH: Weinheim, Germany, 2007; pp. 352-356.

3. Gryguc, A.; Shaha, S.; Behravesh, S.; Jahed, H.; Wells, M.; Williams, B.; Su, X. Monotonic and cyclic behaviour of cast and cast-forged AZ80 Mg. Int. J. Fatigue 2017, 104, 136-149. [CrossRef]

4. Gryguc, A.; Shaha, S.K.; Behravesh, S.B.; Jahed, H.; Wells, M.; Williams, B. Improvement of Fatigue Properties of AZ31B Extruded Magnesium Alloy through Forging. Frattura Integrità Strutt. 2020, 14, 152-165. [CrossRef]

5. Wang, Q.; Zhang, Z.-M.; Zhang, X.; Yu, J.-M. Precision forging technologies for magnesium alloy bracket and wheel. Trans. Nonferrous Met. Soc. China 2008, 18, s205-s208. [CrossRef]

6. Zhao, X.; Gao, P.; Zhang, Z.; Wang, Q.; Yan, F. Fatigue characteristics of the extruded AZ80 automotive wheel. Int. J. Fatigue 2020, 132, 105393. [CrossRef]

7. Yuan, L.; Zhao, Z.; Shi, W.; Xu, F.; Shan, D. Isothermal forming of the large-size AZ80A magnesium alloy forging with high mechanical properties. Int. J. Adv. Manuf. Technol. 2015, 78, 2037-2047. [CrossRef]

8. Su, Z.; Wan, L.; Sun, C.; Cai, Y.; Yang, D. Hot deformation behavior of AZ80 magnesium alloy towards optimization of its hot workability. Mater. Charact. 2016, 122, 90-97. [CrossRef]

9. He, H.; Huang, S.; Yi, Y.; Guo, W. Simulation and experimental research on isothermal forging with semi-closed die and multi-stage-change speed of large AZ80 magnesium alloy support beam. J. Mater. Process. Technol. 2017, 246, 198-204. [CrossRef]

10. Chen, Q.; Zhang, X.; Lin, J.; Zhan, H.; Zhao, Z.; Xie, Z.; Yuan, B. Isothermal closed-die forming process of magnesium alloy upper receiver: Numerical simulation and experiments. Int. J. Adv. Manuf. Technol. 2019, 102, 685-694. [CrossRef]

11. Kevorkijan, V. AZ80 and ZC71/SiC/12p closed die forgings for automotive applications: Technical and economic assessment of possible mass production. Mater. Sci. Technol. 2003, 19, 1386-1390. [CrossRef]

12. Moldovan, P.; Popescu, G.; Bojin, D.; Constantinescu, D.; Pana, M. Improving the fatigue resistance of magnesium alloys for forged parts in automotive industry. Metal. Int. 2009, 14, 23-26.

13. Yoon, J.; Lee, S.-I. Warm forging of magnesium AZ80 alloy for the control arm in an automobile. Proc. Inst. Mech. Eng. Part D J. Automob. Eng. 2015, 229, 1732-1738. [CrossRef]

14. Yoon, J.; Lee, J. Process design of Warm-Forging with extruded Mg-8Al-0.5Zn alloy for differential case in automobile transmission. Int. J. Precis. Eng. Manuf. 2015, 16, 841-846. [CrossRef]

15. Gryguc, A.; Shaha, S.K.; Behravesh, S.B.; Jahed, H.; Wells, M.; Williams, B. Compression Behaviour of Semi-closed Die Forged AZ80 Extrusion. In Characterization of Minerals, Metals, and Materials; Springer: Cham, Switzerland, 2017; pp. 361-369.

16. Gryguc, A.; Behravesh, S.; Shaha, S.; Jahed, H.; Wells, M.; Williams, B.; Su, X. Low-cycle fatigue characterization and texture induced ratcheting behaviour of forged AZ80 Mg alloys. Int. J. Fatigue 2018, 116, 429-438. [CrossRef]

17. Gryguć, A.; Behravesh, S.; Shaha, S.; Jahed, H.; Wells, M.; Williams, B.; Su, X. Multiaxial cyclic behaviour of extruded and forged AZ80 Mg alloy. Int. J. Fatigue 2019, 127, 324-337. [CrossRef]

18. Gryguć, A.; Karparvarfard, S.M.H.; Roostaei, A.; Toscano, D.; Shaha, S.; Behravesh, B.; Jahed, H. On the Load Multiaxiality Effect on the Cyclic Behaviour of Magnesium Alloys. In Magnesium Technology; Springer: Cham, Switzerland, 2020; pp. 151-159.

19. Gryguć, A.; Behravesh, S.; Jahed, H.; Wells, M.; Williams, B.; Su, X. Multiaxial Fatigue and Cracking Orientation of Forged AZ80 Magnesium Alloy. Procedia Struct. Integr. 2020, 25, 486-495. [CrossRef] 
20. Williams, B.W.; Kodippili, T.A.; McKinley, J.; Lambert, S.; Jahed, H. Numerical Modeling of the Forging Response of a Magnesium Alloy Control Arm. Miner. Met. Mater. Ser. 2021, 229-244. [CrossRef]

21. Gryguc, A.; Behravesh, S.; Jahed, H.; Wells, M.; Williams, B.; Gruber, R.; Duquett, A.; Sparrow, T.; Lambrou, M.; Su, X. Effect of thermomechanical processing defects on fatigue and fracture behaviour of forged magnesium. Frattura Integrità Strutt. 2020, 15, 213-227. [CrossRef]

22. Gryguc, A.; Jahed, H.; Williams, B.; McKinley, J. Magforge-Mechanical behaviour of forged AZ31B extruded magnesium in monotonic compression. In Materials Science Forum; Trans Tech Publications Ltd.: Zurich, Switzerland, 2015; pp. 291-297. [CrossRef]

23. Gryguc, A.; Shaha, S.; Jahed, H.; Wells, M.; Williams, B.; McKinley, J. Tensile and fatigue behaviour of as-forged AZ31B extrusion. Frattura Integrità Strutt. 2016, 10, 251-258. [CrossRef]

24. Gryguć, A. Fatigue of Forged AZ80 Magnesium Alloy; University of Waterloo: Waterloo, ON, Canada, 2019.

25. Roostaei, A.A.; Jahed, H. Role of loading direction on cyclic behaviour characteristics of AM30 extrusion and its fatigue damage modelling. Mater. Sci. Eng. A 2016, 670, 26-40. [CrossRef]

26. Prakash, P.; Toscano, D.; Shaha, S.K.; Wells, M.A.; Jahed, H.; Williams, B.W. Effect of temperature on the hot deformation behavior of AZ80 magnesium alloy. Mater. Sci. Eng. A 2020, 794, 139923. [CrossRef]

27. Prakash, P.; Hadadzadeh, A.; Shaha, S.K.; Whitney, M.A.; Wells, M.A.; Jahed, H.; Williams, B.W. Microstructure and Texture Evolution During Hot Compression of Cast and Extruded AZ80 Magnesium Alloy. In Magnesium Technology 2019; Springer: Cham, Switzerland, 2019; pp. 89-94.

28. Luo, A.A. Magnesium casting technology for structural applications. J. Magnes. Alloy. 2013, 1, 2-22. [CrossRef]

29. Jahed, H.; Albinmousa, J. Multiaxial behaviour of wrought magnesium alloys-A review and suitability of energy-based fatigue life model. Theor. Appl. Fract. Mech. 2014, 73, 97-108. [CrossRef]

30. Chaudhury, P.K.; Sean, P.R.; Agnew, R. Forging of Magnesium Alloys, Metalwork. Bulk Form 2018, 2018 14, 318-323. [CrossRef]

31. Lou, X.; Li, M.; Boger, R.; Agnew, S.; Wagoner, R. Hardening evolution of AZ31B Mg sheet. Int. J. Plast. 2007, 23, 44-86. [CrossRef]

32. Kurz, G.; Clauw, B.; Sillekens, W.H.; Letzig, D.; Manufacturing, P. Die Forging of the Alloys Az80 and Zk60. In Proceedings of the Magnesium Technology 2009, San Francisco, CA, USA, 15-19 February 2009.

33. Al-Samman, T. Magnesium: The Role of Crystallographic Texture, Deformation Conditions and Alloying Elements on Formability; Cuvillier Verlag: Göttingen, Germany, 2008; p. 233.

34. Lai, W.-J.; Li, Y.-Y.; Hsu, Y.-F.; Trong, S.; Wang, W.-H. Aging behaviour and precipitate morphologies in Mg-7.7Al-0.5Zn-0.3Mn (wt.\%) alloy. J. Alloy. Compd. 2009, 476, 118-124. [CrossRef]

35. Braszczyńska-Malik, K. Discontinuous and continuous precipitation in magnesium-aluminium type alloys. J. Alloy. Compd. 2009, 477, 870-876. [CrossRef]

36. Jiang, L.; Huang, W.; Zhang, D.; Guo, F.; Xue, H.; Xu, J.; Pan, F. Effect of Sn on the microstructure evolution of AZ80 magnesium alloy during hot compression. J. Alloy. Compd. 2017, 727, 205-214. [CrossRef]

37. Zhou, H.; Li, Q.; Zhao, Z.; Liu, Z.; Wen, S.; Wang, Q. Hot workability characteristics of magnesium alloy AZ80—A study using processing map. Mater. Sci. Eng. A 2010, 527, 2022-2026. [CrossRef] 